\title{
DIREITO À SAÚDE NO BRASIL entre a prevenção de doenças e o tratamento de doentes
}

\author{
Olavo Viana Costa \\ Sociólogo, Analista da Fundação Seade
}

$\mathrm{E}$ ste artigo constitui uma reflexão circunstanciada sobre as relações entre saúde e assistência médica na sociedade brasileira, com o objetivo de avaliar as possibilidades de efetivação do direito à saúde, tal como instituído pela Constituição de 1988. Explorando diversas fontes de dados, inclusive um levantamento domiciliar que possibilita uma acurada caracterização da demanda por serviços de saúde na Região Metropolitana de São Paulo (Fundação Seade, 1992, 1995 e 1999), procura-se demonstrar que a universalização das ações públicas de atenção à saúde, mediante a oferta de serviços médicos gratuitos ou parcialmente subsidiados pela seguridade social, é o mais factível dos objetivos preconizados pelo dispositivo constitucional que consagrou o direito à saúde no Brasil.

Entretanto, deve-se fazer a ressalva de que se trata de um objetivo alcançável antes mesmo da promulgação da nova Carta constitucional, como demonstra a notável ampliação, sob a ordem política instituída a partir do golpe militar de 1964, da assistência médica como contraprestação devida pelo Estado aos trabalhadores que contribuíam para o antigo sistema de previdência social (Oliveira e Teixeira, 1976). As tensões e ambigüidades da ampliação da assistência médica da previdência social nesse período, que a literatura descreve como um processo de universalização excludente (Favaret Filho e Oliveira, 1989), explicam a configuração de um sistema de saúde plural (Mendes, 1996), em que os serviços públicos concorrem potencialmente com os serviços privados, especialmente aqueles cuja contrapartida financeira dos usuários se faz mediante a contratação de seguros ou planos privados de assistência à saúde (Augusto e Costa, 2000).

\section{O DIREITO À SAÚDE COMO UMA NORMA JURÍDICA DE DIFÍCIL APLICAÇÃO PRÁTICA}

A referência básica para a reflexão é o artigo 196 da Carta Magna, que define a saúde como direito de todos e dever do Estado, a ser garantido mediante políticas sociais e econômicas que visem a redução do risco de doenças e de outros agravos e o acesso universal e igualitário às ações e serviços para a sua promoção, proteção e recuperação (Brasil, 1988). Partindo-se da premissa de que se trata de uma norma jurídica de difícil aplicação prática - pois prevê a realização de objetivos entre os quais não há, necessariamente, relação de equivalência - , admite-se que a relação implícita entre os objetivos preconizados pelo dispositivo constitucional que consagrou o direito à saúde não apresenta os dois principais atributos ou propriedades que determinam a equivalência no âmbito da teoria matemática dos conjuntos: a simetria, definida como a correspondência entre $\mathrm{A}$ e $\mathrm{B}$, que é também válida entre $\mathrm{B}$ e $\mathrm{A}$; e a transitividade, definida como a correspondência que é válida entre $\mathrm{A}$ e $\mathrm{C}$ se for válida entre $\mathrm{A}$ e $\mathrm{B}$ e entre $\mathrm{B}$ e $\mathrm{C}$.

A ausência de simetria leva à suposição de que aqueles objetivos são independentes e, por extensão, à hipótese de que a universalização das ações públicas de atenção à saúde pode ser alcançada sem que se efetive a igualização do acesso aos serviços para a sua promoção, proteção e recuperação ou que se reduza o risco de doen- 
ças e de outros agravos. A falta de transitividade leva à suposição de que são objetivos indeterminados e, por extensão, à hipótese de que, ainda que a universalização das ações públicas de atenção à saúde possa resultar em diminuição do risco de doenças e de outros agravos, esta não é uma condição necessária ou suficiente para a igualização do acesso aos serviços de promoção, proteção e recuperação da saúde. Tendo em vista as suposições e hipóteses mencionadas, a questão central é saber se e em que medida o sistema de saúde, além de prestar assistência gratuita a todos os cidadãos, independentemente de sexo, idade ou posição social, é capaz de alterar qualitativamente as condições de vida dos usuários, diminuindo, por meio de ações preventivas e curativas de alcance universal, os riscos de que voltem a adoecer freqüentemente ou venham a morrer precocemente.

Admite-se aqui, de antemão, a descrença diante dessa possibilidade, a considerar a crescente subordinação das práticas de controle epidemiológico aos procedimentos terapêuticos individualizados, cuja generalização em escala mundial somente se tornou possível a partir da incorporação dos medicamentos e equipamentos que dão suporte à moderna medicina tecnológica (Donnangelo e Pereira, 1979). Assim, não obstante o reconhecimento de que a oferta de serviços médicos gratuitos ou parcialmente subsidiados pelo Estado representa uma negação virtual dos automatismos do mercado e de sua perversa tendência à concentração de riqueza e à exclusão social (Oliveira, 1988), a progressiva universalização da assistência médica da seguridade social não configura, do ponto de vista da acessibilidade, um processo de igualização capaz de assegurar à população de menor poder aquisitivo o mesmo atendimento disponível para os segmentos com melhores condições financeiras (Costa, 1996).

Além disso, a generalização do consumo individual de serviços médicos não produz, em termos da redução do risco de doenças e outros agravos à saúde, efeitos comparáveis àqueles obtidos por meio de práticas de controle epidemiológico tradicionalmente executadas sob o poder do Estado (Gonçalves, 1991). E isso por uma razão muito simples, já demonstrada em estudos anteriores sobre a intervenção estatal no setor: no Brasil, ao contrário de outros países com mecanismos de seguridade social que propiciam o acesso da população carente a bens e serviços indispensáveis à sobrevivência, a ampliação das possibilidades de consumo individual de serviços médicos ocorreu concomitantemente ao abandono das práticas institucionalizadas de saúde pública (Augusto, 1986).

\section{TENSÕES E AMBIGÜIDADES DA REFORMA SANITÁRIA NO BRASIL}

Forma privilegiada da intervenção estatal no campo da saúde durante todo o século XIX e parte do século XX (Rosen, 1994), as práticas institucionalizadas de saúde pública desempenharam papel preponderante no controle de doenças transmitidas pela água ou dependentes do saneamento básico do meio urbano, bem como daquelas que dependiam do controle sobre outras espécies vivas, participantes de sua cadeia de transmissão humana, principalmente insetos e roedores (Gonçalves, 1991). Sua importância para a discussão das possibilidades de efetivação do direito à saúde no Brasil advém do fato de estas práticas terem contribuído decisivamente para o sucesso das estratégias de urbanização e industrialização nos países cujas economias de mercado atualmente se caracterizam por um elevado nível de renda per capita, possibilitando, a um só tempo, o controle epidemiológico e a assistência médica à população carente (Foucault, 1985). A realização simultânea dos mesmos objetivos parece impossível hoje, haja vista o aumento da incidência, em período recente, tanto de doenças facilmente evitáveis por medidas preventivas como daquelas para as quais simplesmente não há tratamento ou existem apenas tratamentos custosos e pouco eficazes, inacessíveis à grande maioria da população (Banco Mundial, 1993).

Consiste nessa aparente incompatibilidade de objetivos historicamente conciliáveis a contradição básica que se observa, no caso brasileiro, ao se analisar as iniciativas de reorganização das ações e serviços públicos de atenção à saúde formuladas e implementadas a partir de meados da década de 70: o Programa de Interiorização das Ações de Saúde e Saneamento - Piass, aprovado em 24 de agosto de 1976 (Brasil, 1976); o Programa Nacional de Serviços Básicos de Saúde - Prevsaúde, cujo anteprojeto (Brasil, 1980), elaborado em 1980, não chegou a ser oficialmente aprovado; o Plano de Reorientação da Assistência à Saúde no Âmbito da Previdência Social, elaborado pelo Conselho Consultivo de Administração de Saúde Previdenciária - Conasp e aprovado em 23 de agosto de 1982 (Brasil, 1982); as Ações Integradas de Saúde - AIS, instituídas em 3 de maio de 1984 (Brasil, 1984); e os Sistemas Unificados e Descentralizados de Saúde Suds, instituídos em 20 de julho de 1987 (Brasil, 1987).

Motivadas por razões técnicas e políticas diversas, essas diferentes iniciativas de reorganização dos serviços públicos de saúde configuram um movimento ambíguo 
de reforma sanitária (Gerschman, 1995), a um só tempo marcado pela universalização da assistência médica da previdência social e pelo desmantelamento do aparato político-administrativo de suporte às práticas institucionalizadas de saúde pública (Gonçalves, 1991). Todas, sem exceção, propuseram-se a disciplinar a demanda direta ou indiretamente financiada pelo Estado, restringindo a oferta de serviços hospitalares, tradicionalmente a cargo de empresas privadas contratadas pelas instituições de previdência social (Oliveira e Teixeira, 1976), e ampliando a oferta de serviços ambulatoriais de menor complexidade tecnológica: as chamadas ações básicas, primárias ou simplificadas de atenção à saúde, supostamente capazes de resolver até $80 \%$ dos casos de procura de atendimento sem a realização de procedimentos médicos que exigem a internação dos pacientes (OMS, 1980).

Ao fazê-lo, compartilharam princípios e diretrizes que viriam a ser consagrados pela legislação que regulamenta as ações e serviços de saúde em todo o território nacional: universalidade do acesso aos serviços, em todos os níveis de assistência; integralidade da assistência, com ações preventivas e curativas, tanto individuais como coletivas; igualdade da assistência, sem preconceitos ou privilégios de qualquer espécie; divulgação de informações quanto ao potencial dos serviços e à sua utilização pela população; conjugação de recursos financeiros, tecnológicos, materiais e humanos da União, dos estados e dos municípios; ênfase na municipalização dos serviços e na sua organização segundo critérios de regionalização e hierarquização; e capacidade de resolução técnica dos serviços, em todos os níveis de assistência (Brasil, 19/09/90).

Não há dúvida de que esses princípios, em sua grande maioria derivados da proposta de medicina comunitária surgida nos Estados Unidos e difundida internacionalmente pela Organização Mundial de Saúde a partir da década de 60 (Donnangelo e Pereira, 1979), possam favorecer o cumprimento do dispositivo constitucional que prevê o acesso universal e igualitário às ações e serviços para a promoção, a proteção e a recuperação da saúde. O que se duvida é que princípios semelhantes estejam sendo efetivamente observados no âmbito do Sistema Único de Saúde - SUS, em que pese o governo brasileiro ter assumido, perante as organizações internacionais do setor, o compromisso político de promover saúde para todos no ano 2000 (OMS, 1980). Basta lembrar que, em 1997, quase dez anos depois da instituição do SUS, mais de 50\% das despesas do governo federal com saúde se destinaram ao pagamento de consultas, exames e internações em esta- belecimentos próprios ou contratados pela seguridade social (Campino et alii, 1998).

Desconsiderar esse dado, que reitera a primazia da assistência médica sobre as práticas tradicionais de saúde pública, significa abstrair, para efeito da discusão sobre as possibilidades de efetivação do direito à saúde no Brasil, o papel desempenhado pelas instituições de previdência social na conformação do perfil de intervenção estatal que propiciou a universalização excludente (Favaret Filho e Oliveira, 1989) e a configuração do sistema de saúde plural (Mendes, 1996). Subestimar a capacidade de resistência das instituições da previdência social às determinações do novo texto constitucional foi, provavelmente, o maior erro da estratégia política traçada pelo movimento de reforma sanitária (Gerschman, 1995), que alcançou seu apogeu na década de 80 , entre a realização da $8^{a}$ Conferência Nacional de Saúde, em 1986, e o encerramento dos trabalhos da Assembléia Nacional Constituinte, em 1988 (Luz, 1994). Talvez animados por um voluntarismo técnico e político que, visto agora em retrospectiva, se revela demasiadamente ingênuo ou excessivamente oportunista, os dirigentes do movimento de reforma sanitária sobreestimaram as reais possibilidades de adesão e apoio popular a uma estratégia de disciplinamento da demanda por serviços de saúde que, ao aventar a idéia de um mínimo socialmente necessário de cuidados médicos para todos, restringiria o universo simbólico das aspirações de consumo típicas da sociedade de massas (Baudrillard, 1994).

\section{RECORRÊNCIA DAS TENSÕES E AMBIGÜIDADES HISTÓRICAS DA REFORMA SANITÁRIA: A EXPERIÊNCIA DO SUS}

Em face da suposição exposta anteriormente, cogitouse reconstituir e analisar as diferentes iniciativas governamentais que precederam a consagração do direito à saúde no Brasil, visando problematizar fatos e argumentos relevantes para a explicação de seu aparente fracasso em disciplinar a demanda por serviços de saúde. Porém, esse objetivo foi descartado, tendo em vista a constatação de que os gestores do SUS têm enfrentado problemas similares ao implementar as mudanças organizacionais indispensáveis à municipalização dos serviços de saúde (Barreto Júnior, 1999). Prova disso é a prioridade que o Ministério de Saúde, nos últimos anos, passou a conferir ao Programa de Agentes Comunitários de Saúde - PACS e ao Programa de Saúde da Família - PSF, concedendo-lhes 
incentivos financeiros especiais, consistentes em acréscimos percentuais que podem representar de $30 \%$ a $80 \%$ do valor global das transferências de recursos do governo federal para a implementação de ações de atenção básica de saúde em estados e municípios (Scotti, 1996).

O PACS teve início em 1991, em municípios da região Nordeste com altas taxas de mortalidade infantil, quando o Ministério da Saúde, motivado por experiências bem-sucedidas de atenção básica à saúde com o concurso de agentes comunitários - moradores especialmente treinados para orientar as famílias da vizinhança acerca de questões de higiene, alimentação e prevenção de doenças -, institucionalizou essas iniciativas. Dentre as iniciativas que serviram de referência para a modelagem do PACS, o Programa de Agentes de Saúde - PAS, desde 1987 em execução no Ceará, foi a que obteve maior êxito. Originariamente, compunha um programa emergencial de geração de emprego em áreas atingidas pela seca, que articulava ações de âmbito municipal e estadual, operando com agentes de saúde selecionados e contratados pelo governo do estado e com enfermeiros contratados pelos municípios (Nepp, 1999).

Em 1994, quando um programa similar já estava em execução em Niterói, o Ministério da Saúde lançou o Programa de Saúde da Família - PSF, em resposta a uma demanda levada pelo Conselho Nacional de Secretários Municipais de Saúde. O novo programa completava a institucionalização dessas experiências locais, agregando-lhe um novo personagem: o médico. Assim, o PSF reúne agentes comunitários, enfermeiros e médicos generalistas, em equipes de trabalho voltadas para a reorganização das unidades básicas de saúde segundo os preceitos de vigilância epidemiológica e atendimento integral à saúde da família (Viana e Dal Poz, 1998).

O objetivo maior do programa, portanto, é a reorganização da prática assistencial em novas bases e critérios, em substituição ao modelo tradicional, centrado no hospital e orientado para a cura de doença. Para tanto, além de recorrer à prevenção como forma de se antecipar à demanda por serviços de saúde, deve observar os princípios de integralidade e hierarquização (atenção integral e referência e contra-referência para os diversos níveis do sistema quando os problemas identificados na atenção básica assim o exigirem), de territorialização e adscrição de clientela (território de abrangência e população residente na área previamente definida). Em conformidade a esses objetivos, a tabela de remuneração dos procedimentos ambulatoriais realizados no âmbito do SUS prevê có- digos específicos para as atividades executadas por enfermeiros e agentes comunitários de saúde.

Análises disponíveis sugerem que, além de reduzir a participação das internações hospitalares no total das despesas realizadas pelo SUS, a implementação do PACS e do PSF produz alterações sensíveis nas condições de vida dos beneficiários, sobretudo nos municípios menos populosos, para os quais há registros de diminuição das taxas de mortalidade materna e infantil e dos índices de incidência e prevalência de doenças facilmente evitáveis por ações preventivas e curativas rotineiramente realizadas nas unidades básicas de saúde da família. Tendo por base esses resultados, admite-se que as unidades básicas de saúde da família possam funcionar como porta de entrada do sistema de saúde, disciplinando e intermediando o acesso da população às unidades de maior complexidade tecnológica, de âmbito local ou regional (Vianna e Dal Poz, 1998).

Pesquisa de avaliação, coordenada pelo Núcleo de Estudos de Políticas Públicas da Universidade de Campinas, obteve resultados diferentes após a realização de entrevistas com gestores e executores do PACS e do PSF em 20 municípios com características demográficas e socioeconômicas bastante diversificadas. Seu relatório final conclui que o principal obstáculo à implementação desses programas - e, por extensão, à estratégia de reorganização do SUS segundo os preceitos de vigilância epidemiológica e atendimento integral à saúde da família -, é o aumento da procura por serviços de maior complexidade tecnológica, dificilmente encontráveis nas unidades básicas de saúde. Nos municípios mais populosos, que geralmente dispõem de uma ampla infra-estrutura de atendimento hospitalar mantida pela iniciativa privada, o problema é tão grave que os gestores e executores desses programas receiam que as unidades básicas de saúde da família possam vir a se transformar simplesmente em unidades de pronto-atendimento (Nepp, 1999).

Aponta na mesma direção um levantamento por amostragem de domicílios, de periodicidade quadrienal, realizado pela Fundação Seade. Trata-se da Pesquisa de Condições de Vida - PCV, que investiga, entre outras características socioeconômicas da população, a disponibilidade de recursos para assistência médica e sua efetiva utilização em casos de necessidade de atendimento. A análise de informações coletadas por essa pesquisa revela que, na Região Metropolitana de São Paulo, mensalmente, de cada quatro habitantes, pelo menos um é atendido no mesmo dia em que procura hospital, pronto-socorro, 
clínica, consultório, laboratório ou outro estabelecimento de saúde. Não há diferenças expressivas quanto a sexo, idade, cor, nível de instrução ou classe de renda familiar per capita entre os cidadãos que se deslocam até esses estabelecimentos em busca de solução para os seus problemas de saúde. A grande maioria se diz satisfeita com $\mathrm{o}$ atendimento, independentemente da condição de pagamento, atributo que os qualifica como usuários da seguridade social, beneficiários da medicina de grupo ou clientes da medicina privada. Assim, o sistema de saúde da maior e mais rica metrópole brasileira, além de responder à demanda efetivamente percebida pela população, parece também satisfazer plenamente as expectativas dos seus usuários (Fundação Seade, 1992, 1995 e 1999).

Os resultados da $\mathrm{PCV}$ podem surpreender, à primeira vista, em face dos inúmeros problemas de atendimento filas de espera, ausência de profissionais, equipamentos defeituosos, contaminação de pacientes, etc. - cotidianamente veiculados pelos meios de comunicação de massa e por estes freqüentemente explorados em tom sensacionalista. Contudo, estão em conformidade com o pressuposto teórico de que, excetuados os casos decorrentes de exigências legais e de episódios que ponham em risco a vida do paciente, os indivíduos somente se deslocam até um estabelecimento de saúde porque são portadores de queixas e reconhecem a eficácia da medicina como meio para a cura ou o controle de doenças (Khon e White, 1976). Estão em conformidade também com depoimentos recolhidos por pesquisas qualitativas, segundo os quais a queixa do paciente, se não solucionada, segue percebida como uma necessidade a ser satisfeita e pode dar ensejo a novos casos de procura de atendimento, independentemente do diagnóstico médico (Souza, 1981).

Paradigmáticos, esses depoimentos chamam a atenção para aspectos que, embora recorrentes na representação dos usuários dos serviços de saúde, são pouco valorizados pelas autoridades responsáveis pelo planejamento e pela tomada de decisões no setor. Além da gravidade do episódio que motiva a procura de atendimento, estão presentes outros elementos discursivos - o diagnóstico, o remédio e a cura (Cohn et alii, 1991) - que reiteram a percepção de que a saúde praticamente se transformou em sinônimo de assistência médica e, como tal, no resultado de procedimentos em que a realização de exames e a prescrição de medicamentos são elementos fundamentais, se não obrigatórios (Augusto, 1986).

A incorporação dessa tecnologia, no grau e com a amplitude registrada em escala mundial nas últimas dé- cadas, amplia consideravelmente, além da possibilidade de superação da clínica como meio de trabalho médico pela reestruturação interna do ato terapêutico em conseqüência da utilização de equipamentos que permitem ao médico apreender a doença sem o testemunho do doente (Polack, 1971) - a perspectiva de substituição da medicina artesanal por novas modalidades de organização da produção e consumo de serviços - em decorrência do aumento das exigências financeiras para a aquisição e manutenção dos novos meios de trabalho, o que favorece a concentração e a centralização desse instrumental em unidades de produção de maior porte, sobretudo hospitais (Donnangelo e Pereira, 1979).

\section{IMPLICAÇÕES DA INSTITUCIONALIZAÇÃO DO SUS NO PROCESSO DE MEDICALIZAÇÃO SOCIAL}

Vistas em retrospectiva, as modificações na base técnica e na forma de organização da produção e consumo de serviços médicos, anteriormente apontadas, são impensáveis sem a intermediação das instituições e dos mecanismos de regulação social típicos do Welfare State, que possibilitaram a utilização do fundo público no financiamento tanto da acumulação do capital como da reprodução da força de trabalho (Oliveira, 1988). A tendência ao esgotamento do fundo público como forma privilegiada da expansão do sistema capitalista, perceptível desde meados da década de 70 (Oliveira, 1993), põe em xeque a continuidade do financiamento da produção de serviços médicos - a custos unitários e globais bastante elevados, em razão da velocidade com que são absorvidas inovações resultantes da descoberta de novos medicamentos e da utilização cada vez mais intensiva de máquinas e equipamentos auxiliares do diagnóstico e tratamento de doenças (Donnangelo e Pereira, 1979). Põe em xeque também a continuidade do financiamento do consumo de serviços médicos por contingentes cada vez mais amplos da população - da classe média até o assalariado de menor poder aquisitivo e, mais recentemente, também os segmentos em situação de indigência ou miséria, tradicionalmente assistidos por instituições filantrópicas, sobretudo de caráter religioso (Oliveira e Teixeira, 1976). Se não for equacionada politicamente, circunscreverá a intervenção do Estado no campo da saúde ao momento da necessidade e da doença (Cohn et alii, 1991), mediante a oferta de serviços médicos gratuitos ou parcialmente sub- 
sidiados que continuarão a se diferenciar enormemente quanto à forma como elegem clientelas, selecionam patologias e utilizam recursos tecnológicos de diagnóstico e terapêutica (Donnangelo e Pereira, 1979).

Mesmo nos Estados Unidos, país em que os gastos públicos e privados com assistência médica perfazem cerca de 40\% do total mundial (Banco Mundial, 1993), aproximadamente 35 milhões de pessoas - quase $15 \%$ da população - não dispõem de cobertura em caso de doença, acidente, ferimento ou outro problema capaz de motivar a procura por atendimento. Além disso, registram-se taxas de mortalidade e de morbidade comparativamente maiores que as calculadas para diversos países da Comunidade Européia (Mishell e Bernstein, 1993). Isto reforça a tese de que a medicalização contemporânea - enquanto processo histórico pelo qual a prática médica tomou como objeto corpos sociais tão diversos como o Estado, as cidades, os pobres, os trabalhadores e, finalmente, a população em geral (Foucault, 1985) inverte os objetivos sociais da prática médica - financiamento público para assistência aos doentes, com vistas à recuperação de sua saúde - e os meios de que se utiliza para atingi-los - recursos extremamente diferenciados de diagnóstico e terapêutica. Parcela expressiva desses recursos é de alto custo e de baixa cobertura, em razão da incorporação cada vez mais intensiva de equipamentos e medicamentos de alta sofisticação tecnológica, inacessíveis ao conjunto da população. Há, portanto, uma inequívoca tendência à valorização da assistência médica como meio de obtenção ou preservação da saúde, que produz e reproduz uma necessidade quase irrefreável de consumo de serviços aos quais se atribui, além da capacidade de manter a saúde enquanto "vida no silêncio dos órgãos" (Lériche apud Canguilhen, 1982), também a de prolongá-la quase indefinidamente, já como possibilidade de cura ou de sobrevivência a doenças antes incuráveis.

Ainda que tais serviços não necessariamente diminuam os riscos de que os consumidores voltem a adoecer freqüentemente ou que venham a morrer precocemente, amplia-se, na representação popular, a sinonímia entre cuidado médico e preservação da saúde. Trata-se de uma dimensão constitutiva da medicalização em processo na sociedade contemporânea, na qual o consumo individual de serviços médicos tende a se subordinar antes à lógica da satisfação que à lógica da necessidade (Galbraith, 1992). A opção é inevitável: incorporar ao consumo todos os cidadãos!

\section{NOTA}

Este artigo é um resumo do argumento central de Tese de Doutorado em Sociologia (Costa, 1999).

\section{REFERÊNCIAS BIBLIOGRÁFICAS}

AUGUSTO, M.H.O. Política social e tecnologia em saúde: ação estatal e incorporação de equipamentos médico-hospitalares às práticas de saúde. Tese de Doutorado. São Paulo, FFLCH-USP, 1986.

AUGUSTO, M.H.O. e COSTA, O.V. "Entre o público e o privado: a saúde hoje no Brasil”. Tempo Social (Revista de Sociologia da USP). São Paulo, v.11, n.2, fev. 2000, p.199-217.

BANCO MUNDIAL. Relatório sobre o desenvolvimento mundial, 1993: investindo em saúde. Rio de Janeiro, Fundação Getúlio Vargas, 1993.

BARRETO JÚNIOR, I.F. Reforma do Estado: uma análise do SUS em São Paulo. Dissertação de Mestrado. São Paulo, PUC/SP, 1999.

BAUDRILLARD, J. A sombra das maiorias silenciosas: o fim do social e o surgimento das massas. São Paulo, Brasiliense, 1994.

BRASIL - Assembléia Nacional Constituinte. "Artigo 6o do Capítulo II - Dos Direitos Sociais, Título II - Dos Direitos e Garantias e Fundamentais”. Constituição da República Federativa do Brasil, promulgada em 5 de outubro de 1988.

BRASIL - Comissão Interministerial de Planejamento e Coordenação dos Ministérios da Saúde e da Previdência e Assistência Social. Resolução CIPLAN no 6/ 84 , de 3 de maio de 1984 , que aprova a estratégia de reorientação do modelo assistencial de prestação de serviços de saúde consubstanciada nas Ações Integradas de Saúde entre os Governos federal, estaduais e municipais.

BRASIL - Congresso Nacional. Lei $n^{-}$8.080, de 19 de setembro de 1990, que dispõe sobre a organização e o funcionamento dos serviços de promoção, proteção e recuperação da saúde e dá outras providências.

BRASIL - Congresso Nacional. Lei $n^{\circ}$ 8.142, de 28 de dezembro de 1990, que dispõe sobre a participação da comunidade na gestão do SUS e sobre as transferências intergovernamentais de recursos financeiros na área da saúde e dá outras providências.

BRASIL - Ministério da Previdência e Assistência Social. Portaria $n^{\circ}$ 3.062, de 23 de agosto de 1982, que aprova o Plano de Reorientação da Assistência à Saúde no Âmbito da Previdência Social, elaborado pelo Conselho Consultivo de Administração de Saúde Previdenciária - Conasp, criado pelo Decreto $n^{\circ} 86.329$, de 2 de setembro de 1981 .

BRASIL - Presidência da República. Decreto $n^{\circ}$ 78.307, de 24 de agosto de 1976, que aprova o Programa de Interiorização das Ações de Saúde e Saneamento no Nordeste e dá outras providências.

BRASIL - Presidência da República. Decreto nº 94.657, de 20 de julho de 1987, que dispõe sobre a criação de Sistemas Unificados e Descentralizados de Saúde nos Estados e dá outras providências.

BRASIL - Secretaria de Planejamento da Presidência da República. Programa Nacional de Serviços Básicos de Saúde. Brasília, Seplan, 1980.

CAMPINO, A.C.C. et alii. Health equity in Latin America. São Paulo, 1998 (Paper prepared for the United Nation Program for Development).

CANGUILHEN, G. O normal e o patológico. $2^{-}$ed. Rio de Janeiro, ForenseUniversitária, 1982.

COHN, A. et alii. Saúde como direito e como serviço. São Paulo, Cortez, 1991.

COSTA, O.V. “ Acesso a serviços de saúde na Região Metropolitana de São Paulo: universalização e reprodução de desigualdades sociais." Conferência Nacional de Estatística - Confest. Rio de Janeiro, 1996. (Textos para Discussão, Volume 2.)

Saúde e Assistência Médica no Brasil: entre a prevenção de doenças e o tratamento de doentes. Tese de Doutorado. São Paulo, FFLCH USP, 1999.

COSTA, O.V. e AUGUSTO, M.H.O. "Uma escolha trágica: saúde ou assistência médica?" São Paulo em Perspectiva. São Paulo, Fundação Seade, v.9 n.3, 1995, p.94-100.

DONNANGELO, M.C.F. e PEREIRA, L. Saúde e sociedade. 2a ed.São Paulo, Duas Cidades, 1979. 
FAVARET FILHO, P. e OLIVEIRA, P.J. de. A universalização excludente: reflexões sobre as tendências do sistema de saúde. Rio de Janeiro, UFRJ/IEI, 1989 (Texto para discussão, 216).

FOUCAULT, M. - Microfísica do poder. 2aㅡ ed. Rio de Janeiro, Graal, 1985.

FUNDAÇÃO SEADE. Pesquisa de Condições de Vida na Região Metropolitana de São Paulo: saúde. São Paulo, 1992.

. Pesquisa de Condições de Vida na Região Metropolitana de São Paulo: primeiros resultados. São Paulo, 1995.

. Pesquisa de Condições de Vida no Estado de São Paulo: primeiros resultados. São Paulo, 1999.

GALBRAITH, J.K. La cultura de la satisfacción. Buenos Aires, Emecé, 1992.

GERSCHMAN, S. A democracia inconclusa: um estudo da reforma sanitária brasileira. Rio de Janeiro, Fiocruz, 1995.

GONÇALVES, R.B.M. “A saúde no Brasil: algumas características do processo histórico nos anos 80”. São Paulo em Perspectiva. São Paulo, Fundação Seade, v.5, n.1, jan/mar 1991, p.99-106.

KOHN, R. e WHITE, K.L. Health care: an international study. London, Oxford University Press, 1976.

LÈRICHE, R. La chirurgie de la douler. Paris, Masson, 1937.

LUZ, M.T. "As Conferências Nacionais de Saúde e as políticas de saúde da década de 80". In: GUIMARÃES, R. e TAVARES, R.A.W. (orgs.). Saúde e sociedade no Brasil: anos 80. Rio de Janeiro, Relume-Dumará, 1994.

MENDES, E.V. Uma agenda para a saúde. São Paulo, Hucitec, 1996.
MISHEL, L. e BERNSTEIN, J. The state of working America: 1992-93. Armonk, M.E. Sharpe, 1993 (Economic Policy Institute Series).

NEPP. Avaliação qualitativa de programas sociais prioritários: uma síntese dos principais resultados da pesquisa de campo. São Paulo, Nepp, 1999 (Relatório final de projeto de pesquisa financiado pelo Programa de Apoio à Gestão Social da Casa Civil da Presidência da República).

OLIVEIRA, F. de. "O surgimento do anti-valor: capital, força de trabalho e fundo público”. Novos Estudos Cebrap. São Paulo, n.22, out 1988, p.8-28.

. “A economia política da social-democracia”. Revista USP, São Paulo, n.17, mar-maio 1993, p.136-143.

OLIVEIRA, J.A. e TEIXEIRA, S.F. (Im)Previdência Social: 60 anos da história da previdência social no Brasil. Rio de Janeiro, Vozes, 1976.

OMS. Salud para todos en el año 2000: estrategias. Washington, OMS, 1980.

POLACK, J.C. La medicine du capital. Paris, Maspero, 1971.

ROSEN, G. Uma história da saúde pública. São Paulo, Hucitec, 1994.

SCOTTI, R.F. Para entender a Norma Operacional Básica do SUS 01/96. Brasília, s. ed., 1996 (Arquivo disponível no site do Ministério da Saúde na Internet).

SOUZA, L.R. Representações de saúde e doença nos setores populares urbanos. Salvador, SBPC, 1981.

VIANNA, A.L. de A. e DAL POZ, M.R."A reforma do sistema de saúde no Brasil e o programa de saúde da família”. Physys (Revista de Saúde Coletiva), v.8, n.2, 1998, p.11-48 